\title{
Study on Grindability of Inconel 718 Superalloy Fabricated by Selective Laser Melting (SLM)
}

\author{
Chenchen Tian 1,2 - Xuekun Li1,2,3,* - Zhonglei Liu1,2 - Geng Zhi1,2 - \\ Guoqiang Guo ${ }^{4}$ - Liping Wang1,2,3 - Yiming Rong5 \\ 1 Tsinghua University, Department of Mechanical Engineering, China \\ 2 Tsinghua University, Beijing Key Lab of Precision/Ultra-precision Manufacturing Equipment and Control, China \\ ${ }^{3}$ Tsinghua University, State Key Lab of Tribology, China \\ 4 Shanghai Spaceflight Precision Machinery Institute, China \\ ${ }^{5}$ Southern University of Science and Technology, Department of Mechanical and Energy Engineering, China
}

The selective laser melting (SLM) process is widely used to fabricate parts with sophisticated geometry. The microstructure and mechanical property of SLM Inconel 718 alloy show anisotropy. However, the influence of anisotropic microstructures on the grinding process and surface integrity is not yet clear. In this article, a grinding experiment with a corundum wheel is performed. Before the experiment, the microstructure for both the scanning plane and the side plane is observed to disclose the microstructural anisotropy. During the experiment, the grinding power signal is measured to represent the time-dependent performance. After the experiment, the surface roughness is measured to represent the surface quality. In addition, microhardness is measured to determine the influence of the anisotropic microstructure on the grindability. Experimental results indicate that the scanning plane consists of many strip structures along the scanning direction while the side plane is characterized by scaly structures and layered structures. Moreover, because of the layered structures, the microhardness profile along the building direction varies more in comparison to the scanning direction. Furthermore, better surface homogeneity and smaller roughness fluctuation can be obtained along scanning feed direction in comparison to the building feed direction. Additionally, microstructures will influence its hardness, which will further influence the grinding power. Therefore, the grindability of SLM Inconel 718 exhibits anisotropy because of anisotropic microstructures.

Keywords: grindability, Inconel 718, selective laser melting, anisotropy

Highlights

- The influence of anisotropic microstructure on grinding process and surface integrity has been investigated experimentally.

- The results indicate that the microhardness profile along the building direction varies more in comparison to the scanning direction.

- The ground surface roughness shows different characteristics along scanning feed direction and building feed direction.

- Microstructures will further influence hardness profile and grinding power.

\section{INTRODUCTION}

Selective laser melting (SLM) is an additive manufacturing technique, also known as rapid prototyping. In comparison to conventional processes, such as casting and forging, SLM exhibits promising applications in the fabrication of complex parts [1]. As an additive manufacturing (AM) technique, SLM forms metal parts layer by layer via melting powder material and possesses the ability to manufacture parts with sophisticated geometry that are difficult to manufacture using conventional subtractive manufacturing processes [2].

Inconel 718 is a commonly used material for aircraft turbine disks, blades or shafts because of its excellent high-temperature strength, oxidation resistance and hot corrosion resistance [3] and [4]. Due to its low content of aluminium and titanium, Inconel 718 is well known for its good weldability. Therefore, the alloy is ideally suited for the SLM process [1]. Due to the development of the aviation industry, the need for SLM Inconel 718 parts increases rapidly owing to its good geometry, flexibility, and reduced waste of materials [5].

In fact, SLM Inconel 718 is widely studied in terms of its microstructural and mechanical properties. Columnar dendrites are found along the building direction in the side surface while equiaxed grains are found in the scanning surface [6]. Moreover, as laser energy density increases, the pattern of columnar dendrites varies significantly: coarsened columnar dendrites, clustered dendrites, as well as slender and uniformly distributed columnar dendrites [7]. The microstructure of SLM Inconel 718 exhibits specific features related to the building process. Defects in the form of small voids and cavities are rare [8].

SLM can produce parts with mechanical properties better than forged and cast material at room temperature and equal properties to forged material at elevated temperatures [1]. Additionally, after 
heat treatment, the mechanical properties of SLM Inconel 718 become better. The yield strength, tensile strength, and hardness values of aged, SLM-fabricated alloy are slightly higher than wrought material [5]. Furthermore, horizontally built specimens had better tensile strength and lower strain-to-failure values compared to vertically built specimens, which exhibit the anisotropy of mechanical property for SLM Inconel 718 [9].

Conventional process Inconel 718 is regarded as a hard-to-machine material because of numerous strengthening phases, low thermal conductivity, and a severe work-hardening phenomenon [10]. Numerous studies have improved the understanding of machinability [11] and [12] and grindability [10], [13] to [17] of conventional process Inconel 718. For example, due to the high mechanical properties and low thermal conductivity, high tensile residual stress is produced when machining Inconel 718 [11]. The SA wheel is suitable for grinding Inconel 718, and the grinding depth has a great effect on the surface integrity in grinding it [13]. However, little attention has been paid to the grindability of SLM Inconel 718 . Therefore, the influence of anisotropic microstructures on the grinding process and finished surface integrity remains unclear.

In this paper, the influence of anisotropic material on the grinding process and finished surface integrity is investigated. In the experiment, the power signal of the whole grinding process is measured and analysed. Moreover, the surface roughness and topography measurements are carried out to analyse the ground surface integrity. Due to the unique fabrication process of SLM, different directions possess different material property characterizations, which in turn influences the grinding process and ground surface integrity. Finally, the correlation of anisotropic material metallurgical structure with grinding power signal, finished surface roughness and microhardness are investigated in detail.

\section{EXPERIMENTAL SETUP}

\subsection{Preparation of Specimens}

Metal powder for SLM, shown in Fig. 1, is globular in shape with a particle size ranging from $10 \mu \mathrm{m}$ to 40 $\mu \mathrm{m}$. The chemical composition of pre-alloyed powder is listed in Table 1.

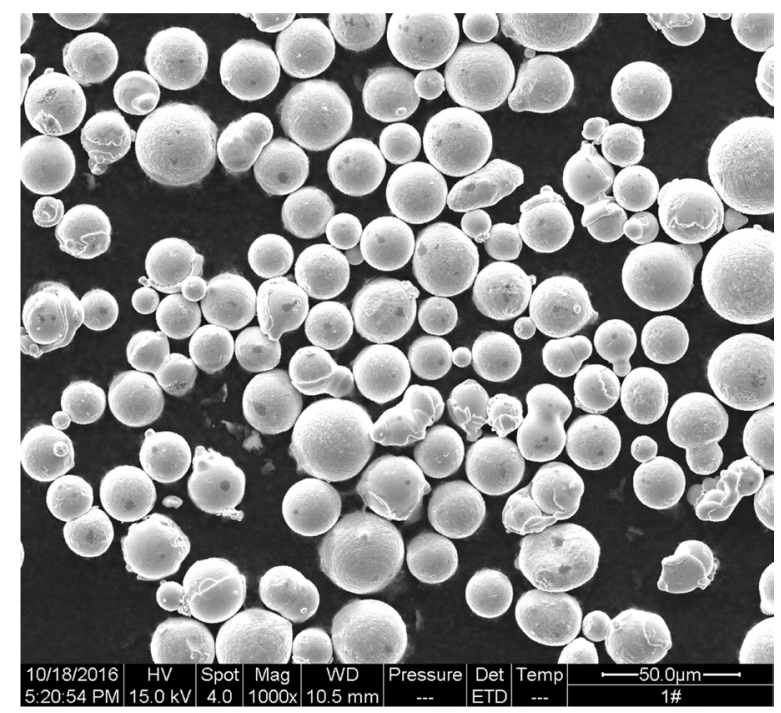

Fig. 1. SEM of Inconel 718 powder morphology

Table 1. The chemical composition of Inconel 718 powder

\begin{tabular}{ccccccccc}
\hline Element & $\mathrm{Ni}$ & $\mathrm{Cr}$ & $\mathrm{Fe}$ & $\mathrm{Nb}$ & $\mathrm{Mo}$ & $\mathrm{Ti}$ & $\mathrm{Al}$ & $\mathrm{C}$ \\
\hline $\mathrm{W}+\%$ & Balance & 19.59 & 13.72 & 5.04 & 3.09 & 0.99 & 0.61 & 0.052 \\
\hline
\end{tabular}

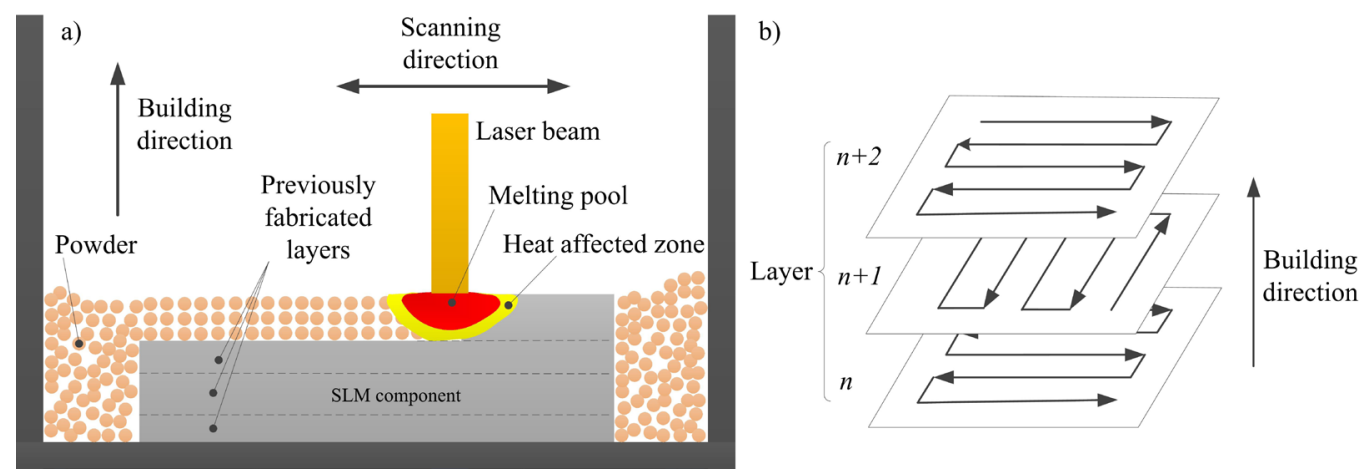

Fig. 2. Principle of SLM machine and scanning path strategy; a) principle of SLM machine; and b) alternative paintbrush scanning strategy 
The principle of SLM process is shown in Fig. 2a. The specimens are produced in an EP-M250 SLM machine based on an alternative paintbrush scanning strategy shown in Fig. 2b [18]. The key parameters of the SLM process used in this study are provided in Table 2.

Table 2. SLM manufacturing parameters

\begin{tabular}{lc}
\hline Manufacturing parameter & Value \\
\hline Laser wavelength $\lambda,[\mathrm{nm}]$ & 1070 \\
\hline Laser power $P,[\mathrm{~W}]$ & 300 \\
\hline Laser scanning speed $V,[\mathrm{~mm} / \mathrm{s}]$ & 1200 \\
\hline Overlap rate $0,[\%]$ & 30 \\
\hline Powder layer thickness $\delta,[\mu \mathrm{m}]$ & 40 \\
\hline
\end{tabular}

\subsection{Grinding Platform}

The grinding experiments are performed on an ELB N10 high precision surface grinding machine tool with corundum wheel in the up-grinding mode, shown in Fig. 3. The machine tool coordinate system is marked in Fig. 3. The $\mathrm{X}$-axis indicates the feed direction, and the Y-axis indicates the grinding tool axial direction. The $\mathrm{Z}$-axis is perpendicular to the grinding surface of the workpiece. The specimen is placed on the vice clamp, which is fixed on the working table by electromagnetic force. To minimize the surface profile error and increase the sharpness, a diamond-shaped roller is used to dress the wheel. A water-based coolant is employed to reduce the grinding zone temperature through a rectangular nozzle. The parameters for dressing and grinding are shown in Tables 3 and 4, respectively.

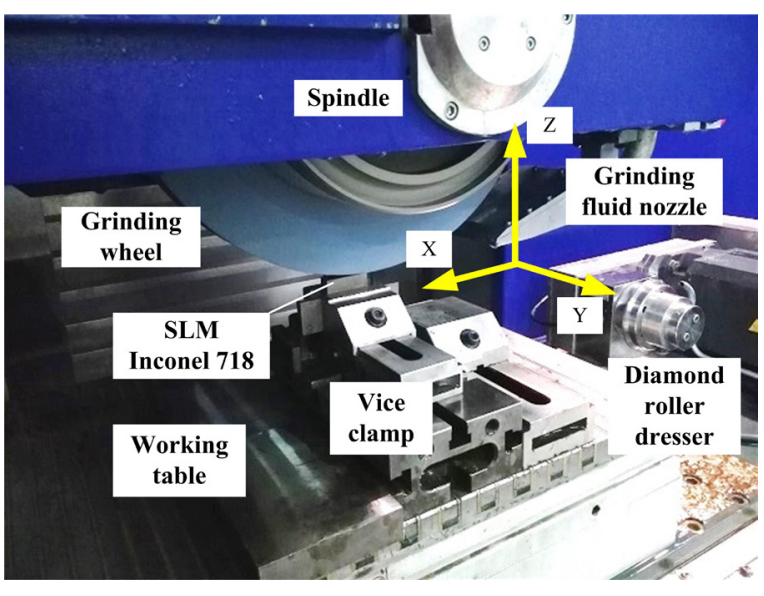

Fig. 3. Experimental platform

\subsection{Grinding Procedure}

Two specimens (specimen A and B) for experiments are rectangular blocks with dimensions of $40 \mathrm{~mm} \times 14$ $\mathrm{mm} \times 40 \mathrm{~mm}$. The schematic diagram of the grinding procedure for specimen A is illustrated in Fig. 4. To make the specimen orientation clear, the workpiece coordinate system is marked in Fig. 4. The Z-axis always indicates the building direction, and the $\mathrm{X}$ - and Y-axes always indicate the scanning direction in the SLM process. For the first grinding pass (Fig. 4a), the wheel interacts with the entire XY surface with a grinding width of $14 \mathrm{~mm}$. The working table moves in a straight reciprocating way with the speed of $50 \mathrm{~mm} /$ min under a grinding depth of $30 \mu \mathrm{m}$ for one stroke, and repeats for 40 strokes along the $\mathrm{X}$-axis direction, leading to a whole depth of material removal of 1.2 $\mathrm{mm}$. For the second grinding pass (Fig. 4b), the wheel interacts with the half $\mathrm{XY}$ surface with a grinding width of $7 \mathrm{~mm}$. The working table speeds up to 300

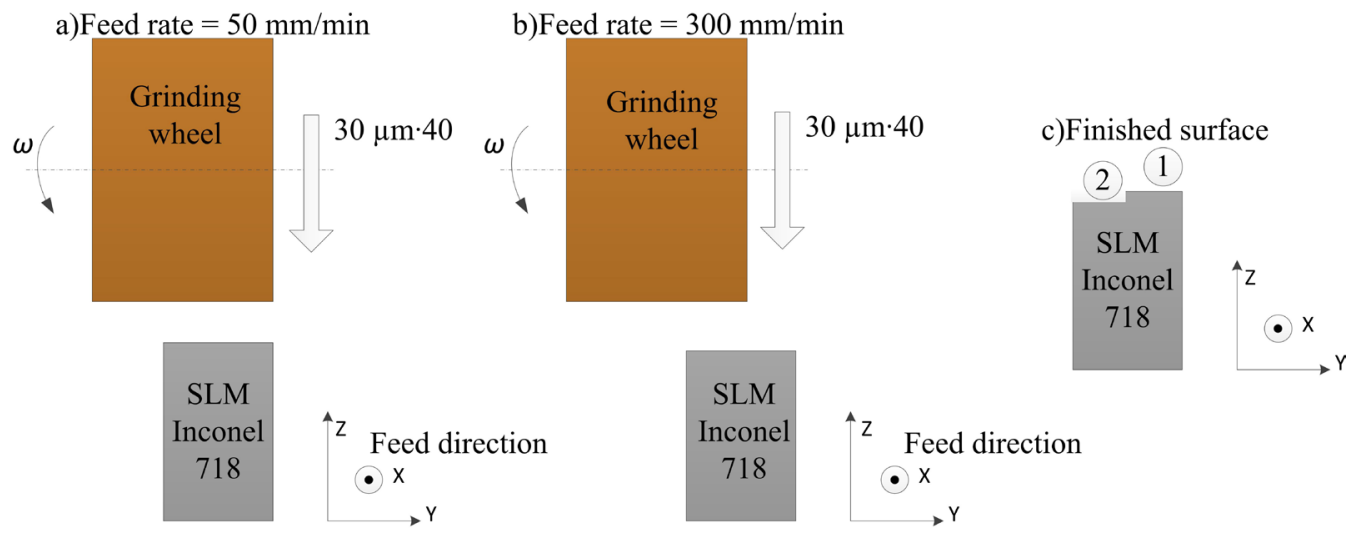

Fig. 4. Schematic diagram of grinding procedure of specimen $A$ 
Table 3. Parameters for dressing process

\begin{tabular}{lc}
\hline Dressing parameter & Value \\
\hline Dressing tool & A diamond shape roller \\
\hline Feed speed & $450 \mathrm{~mm} / \mathrm{min}$ \\
\hline Depth of dressing & $30 \mu \mathrm{m} / \mathrm{stroke} \times 5$ strokes \\
\hline Dressing wheel speed & $24 \mathrm{~m} / \mathrm{s}$ \\
\hline Speed rate & 0.8 (the same direction dressing) \\
\hline
\end{tabular}

$\mathrm{mm} / \mathrm{min}$, and the other parameters remain constant. Consequently, the first ladder shape is created with two finished surfaces marked as surface 1 and 2, shown in Fig. 4c. Similarly, the second ladder shape with surface 3 and 4 is created with a working table speed of $600 \mathrm{~mm} / \mathrm{min}$ and $900 \mathrm{~mm} / \mathrm{min}$. Furthermore, the same grinding operation is performed on specimen $\mathrm{B}$ along the feed direction $\mathrm{Z}$ instead of $\mathrm{X}$. The
Table 4. Parameters for grinding experiments

\begin{tabular}{lc}
\hline Grinding parameter & Value \\
\hline Specimen material & SLM Inconel 718 \\
\hline Specimen dimension & $40 \mathrm{~mm}(\mathrm{~L}) \times 14 \mathrm{~mm}(\mathrm{~W}) \times 40 \mathrm{~mm}(\mathrm{H})$ \\
\hline Grinding tool & $\begin{array}{c}\text { Sintered resin bonded corundum } \\
\text { wheel (grit size } 60 \#)\end{array}$ \\
\hline Grinding wheel dimension & $400 \mathrm{~mm} \times 40 \mathrm{~mm} \times 203 \mathrm{~mm}$ \\
\hline Grinding wheel speed & $30 \mathrm{~m} / \mathrm{s}$ \\
\hline Working table speed & $50 \mathrm{~mm} / \mathrm{min}, 300 \mathrm{~mm} / \mathrm{min}$, \\
\hline Depth of grinding & $600 \mathrm{~mm} / \mathrm{min}, 900 \mathrm{~mm} / \mathrm{min}$ \\
\hline Coolant & $\begin{array}{r}30 \mu \mathrm{m} / \mathrm{stoke} \times 40 \mathrm{strokes} \\
\text { per grinding section }\end{array}$ \\
\hline
\end{tabular}

grinding process parameters for four finished surfaces of specimen A and four finished surfaces of specimen $\mathrm{B}$ are summarized in Table 5 .

Table 5. The grinding process parameters of eight finished surfaces

\begin{tabular}{lcccccc}
\hline Grinding surface & Specimen & $\begin{array}{c}\text { Wheel speed } \\
{[\mathrm{m} / \mathrm{s}]}\end{array}$ & $\begin{array}{c}\text { Grinding depth } \\
{[\mu \mathrm{m}] \times 40 \text { strokes }}\end{array}$ & $\begin{array}{c}\text { Grinding width } \\
{[\mathrm{mm}]}\end{array}$ & $\begin{array}{c}\text { Feed } \\
\text { direction }\end{array}$ & $\begin{array}{c}\text { Feed rate } \\
{[\mathrm{mm} / \mathrm{min}]}\end{array}$ \\
\hline Surface 1 & $\mathrm{A}$ & 30 & 30 & 14 & $\mathrm{X}$ & 50 \\
\hline Surface 2 & $\mathrm{A}$ & 30 & 30 & 7 & $\mathrm{X}$ & 300 \\
\hline Surface 3 & $\mathrm{A}$ & 30 & 30 & 7 & $\mathrm{X}$ & 600 \\
\hline Surface 4 & $\mathrm{A}$ & 30 & 30 & 14 & $\mathrm{X}$ & 900 \\
\hline Surface 5 & $\mathrm{B}$ & 30 & 30 & 14 & $\mathrm{Z}$ & 50 \\
\hline Surface 6 & $\mathrm{B}$ & 30 & 30 & 7 & $\mathrm{Z}$ & 300 \\
\hline Surface 7 & $\mathrm{B}$ & 30 & 30 & 7 & $\mathrm{Z}$ & 600 \\
\hline Surface 8 & $\mathrm{B}$ & 30 & 30 & 14 & $\mathrm{Z}$ & 900 \\
\hline
\end{tabular}

\section{MEASUREMENT METHODS}

\subsection{Microstructure}

Before the grinding experiment, microstructure observation is conducted to disclose the difference between the scanning plane and side plane. The surfaces to be observed are polished with a polishing machine, and then etched with Kalling's reagent. Afterwards, metallographic photos are taken with an ultra-depth three-dimensional microscope.

\subsection{Grinding power}

During the grinding experiment, the grinding power signal is recorded with a Hall power sensor (Fig. 5) installed in the electrical cabinet of the machine tool. The power sensor measures the power signal via combining a three-phase current and voltage between the inverter and spindle. Then the signal acquisition equipment (National Instrument (NI) PXIe-6124 DAQ) accumulates the signal data and transmits it to the computer.

\subsection{Microhardness}

After the grinding experiment, the Qness Q60A+ microhardness tester with a test load ranging from 1 $\mathrm{g}$ to $62.5 \mathrm{~kg}$ is applied to measure the micro Vickers hardness of specimens. Test points are hit on the specimen surface by penetrator with a pressing force of $100 \mathrm{~g}$ and duration time of $10 \mathrm{~s}$. The first point is located at the extension line of the lower finished surface, and all the points are aligned into a straight line in an arithmetic sequence manner with the vertical spacing of $30 \mu \mathrm{m}$ (shown in Fig. 6). The average hardness of every material removal layer can be obtained from the test point with the same number. 


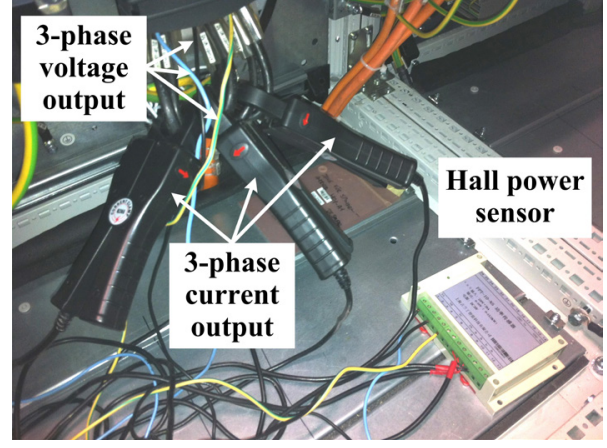

Fig. 5. Measurement approaches of grinding power signal

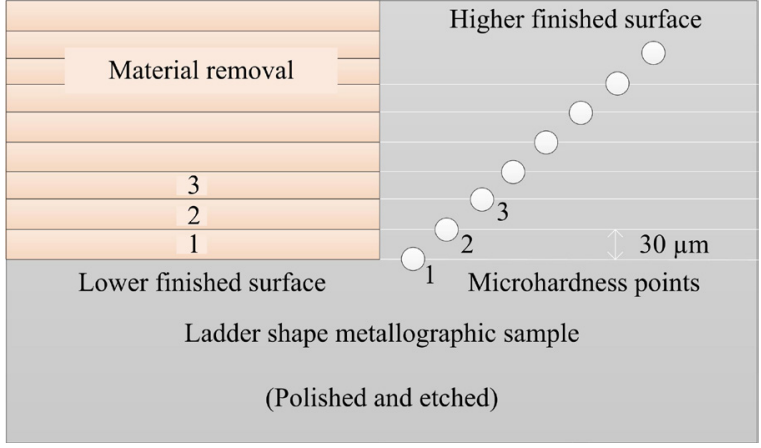

Fig. 6. Location of microhardness test points

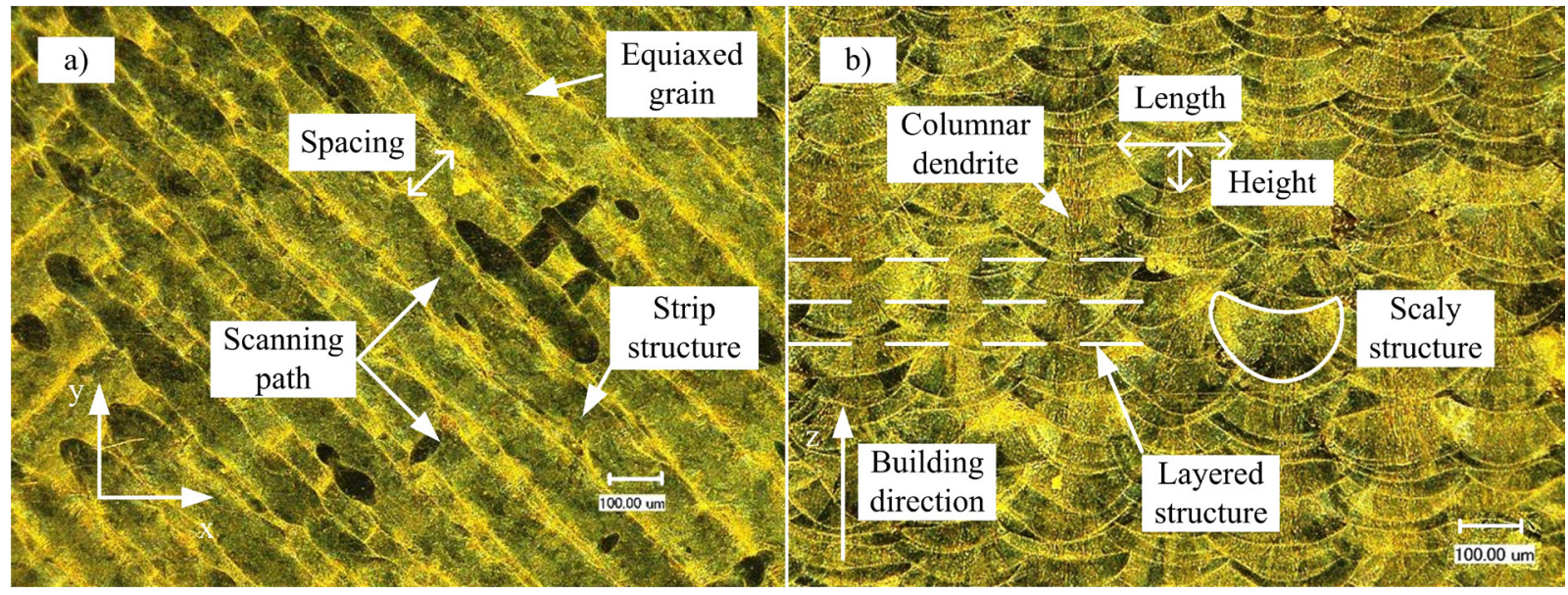

Fig. 7. Microstructure of SLM Inconel 718 specimen; a) the scanning plane; and b) the side plane
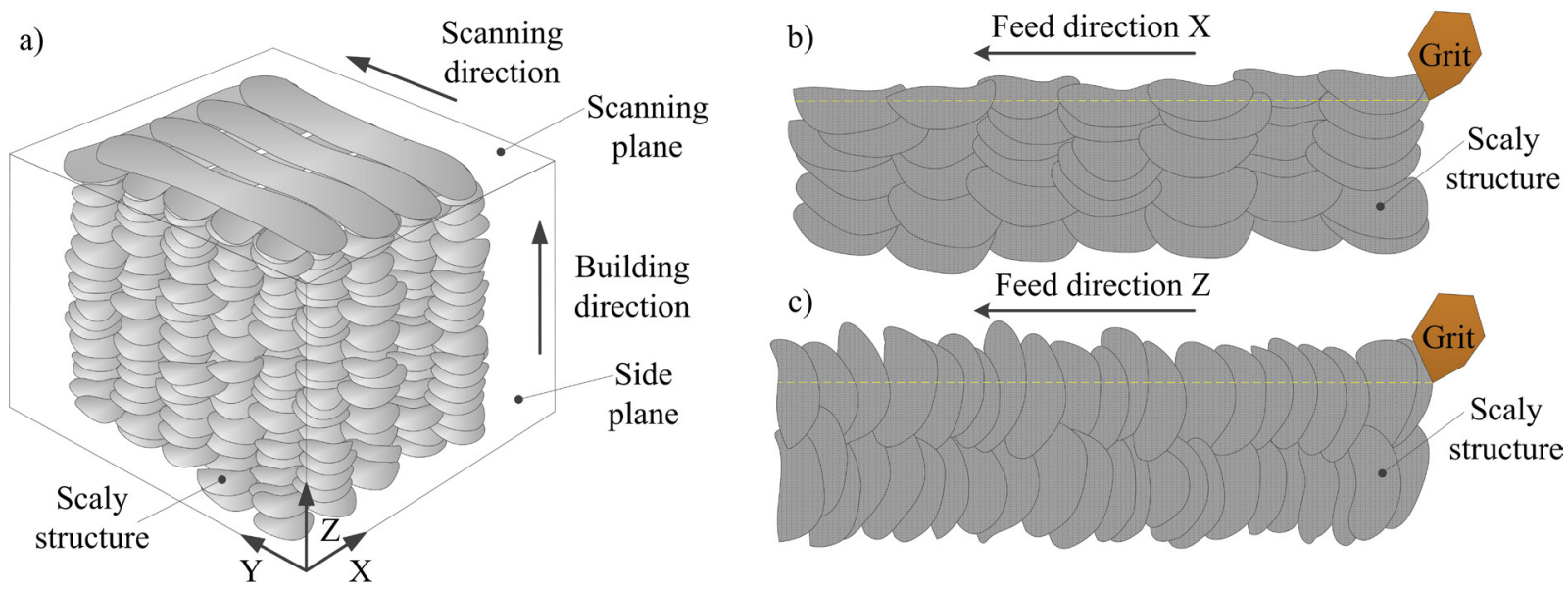

Fig. 8. Material removal model for SLM Inconel 718 grinding;

a) the structure of SLM 718; and b) c) the material removal along different directions

\subsection{Surface Roughness}

After the grinding experiment, the surface roughness is measured in the ZYGO NewView 7300 optical surface profiler, which utilizes scanning white light interferometry to image and measure the microstructure and topography of surfaces in three dimensions. 


\section{RESULTS AND ANALYSIS}

\subsection{Microstructure}

The characterization of microstructure in the scanning plane and side plane is demonstrated in Fig. 7. The microstructures of the scanning plane (perpendicular to the building direction) and side plane (parallel to the building direction) of the SLM Inconel 718 specimen have different patterns in terms of structure composition and crystalline form.

1. Structure composition difference

The scanning plane consists of strip structures along the scanning direction with the average spacing of $120 \mu \mathrm{m}$ while the side plane is characterized by scaly structures with the average length of $180 \mu \mathrm{m}$ and height of $70 \mu \mathrm{m}$. In addition, the side plane shows layered structures with average thickness of $40 \mu \mathrm{m}$, considering the overlap rate of adjacent layers.

2. Crystalline form difference

The scanning plane is characterized by equiaxed grain while the side plane is characterized by columnar dendrites along the building direction because of the temperature gradient.

The unique process of SLM creates the anisotropic microstructure, which will influence the grindability, such as grinding stability, surface integrity etc. Fig. 8 shows a simplified microscopic material removal model for SLM Inconel 718 grinding. Grinding with different feed directions will exhibit different grinding characteristics and ground surface integrity, which can be explained by the model shown in Fig. 8 .

\subsection{Microhardness Profile vs. Microstructure}

To investigate the influence of the anisotropic microstructure on the microhardness profile, test points are arranged in an arithmetic sequence manner on the polished surfaces of the scanning plane and side plane. Every test is repeated five times, and the average value is calculated to decrease the measurement error.

The microhardness profile difference between the scanning plane and side plane is clarified in Fig. 9. The microhardness curve in the scanning plane along the scanning direction is smoother in comparison to that in the side plane along the building direction. Fig. 9 also shows that the side plane possesses larger microhardness variation compared to the scanning plane. Therefore, it reveals that the microstructure in the side plane is more uneven than that in the scanning plane. In addition, the hardness curve shows periodicity (about $90 \mu \mathrm{m}$ to $120 \mu \mathrm{m}$ in one period) along the building direction because of the layered structure. As shown in Fig. 9, three to four points is a cycle for the hardness curve of the side plane along the building direction, and there are five periods labelled above the curve. The periodicity phenomenon is due to the unique layered structure generated by the SLM process, which can be explained in detail as follows: the layer thickness is $40 \mu \mathrm{m}$ and the point spacing is $30 \mu \mathrm{m}$, so the least common multiple 120 $\mu \mathrm{m}$ becomes the period of the hardness curve along the building direction in the side plane. Considering the measurement error and overlap of layers, $90 \mu \mathrm{m}$ to $120 \mu \mathrm{m}$ in one period is a reasonable result. Therefore, it suggests that different microstructures determine different microhardness profiles in two orthogonal planes.

\subsection{Grinding Power vs. Microhardness Profile}

To establish the correlation between grinding power consumption and the microhardness profile, the microhardness tests are conducted and repeated five

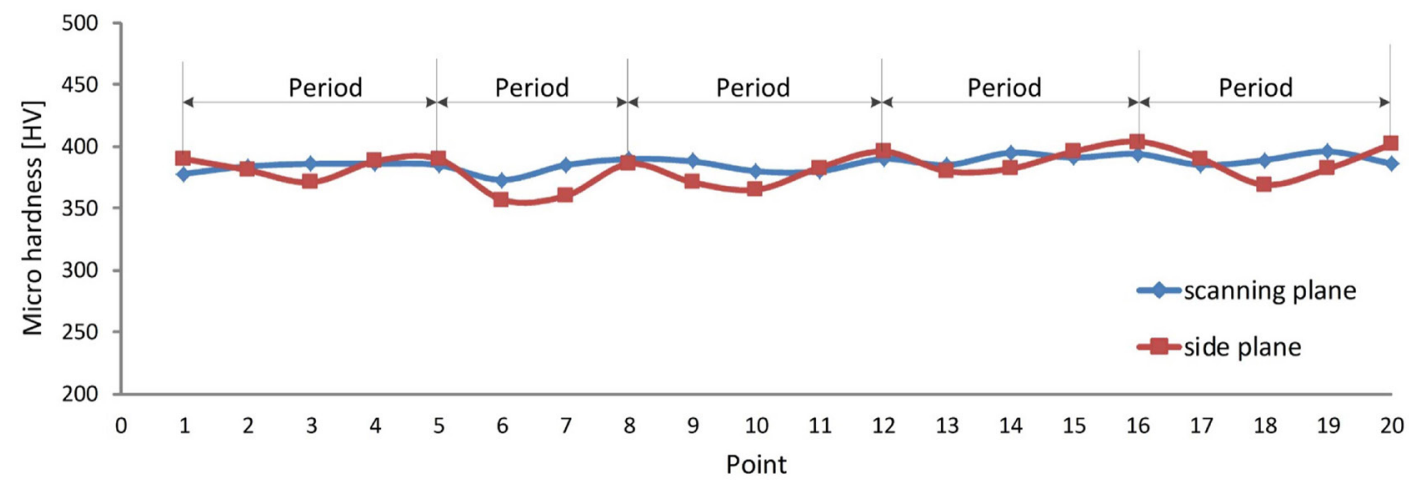

Fig. 9. Microhardness profile comparison of scanning plane and side plane 


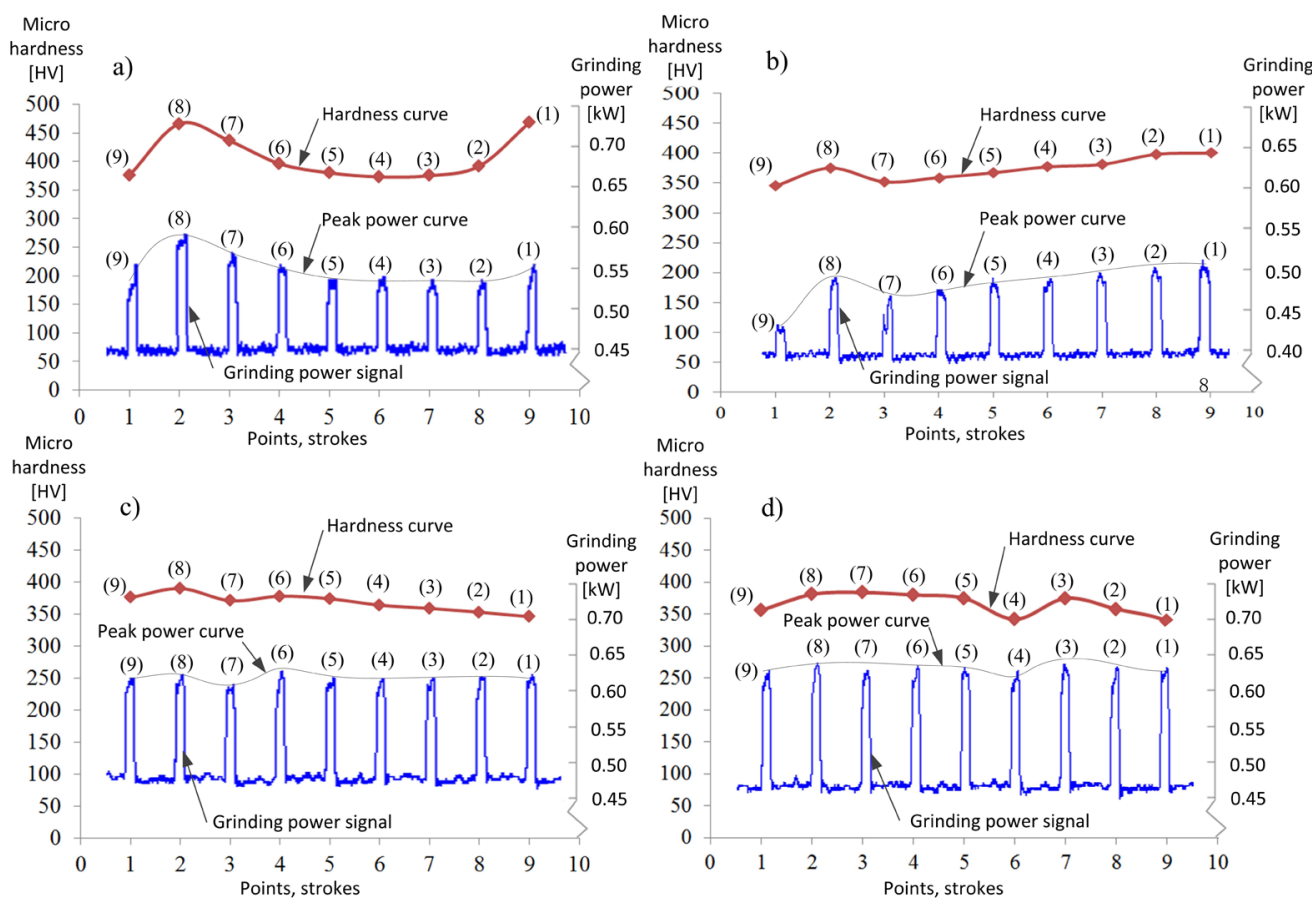

Fig. 10. Hardness curve and corresponding grinding layer power signal; a) feed rate $=300 \mathrm{~mm} / \mathrm{min}, Z$ feed direction; b) feed rate $=300 \mathrm{~mm} / \mathrm{min}, X$ feed direction; c) feed rate $=600 \mathrm{~mm} / \mathrm{min}, Z$ feed direction; d) feed rate $=600 \mathrm{~mm} / \mathrm{min}, X$ feed direction
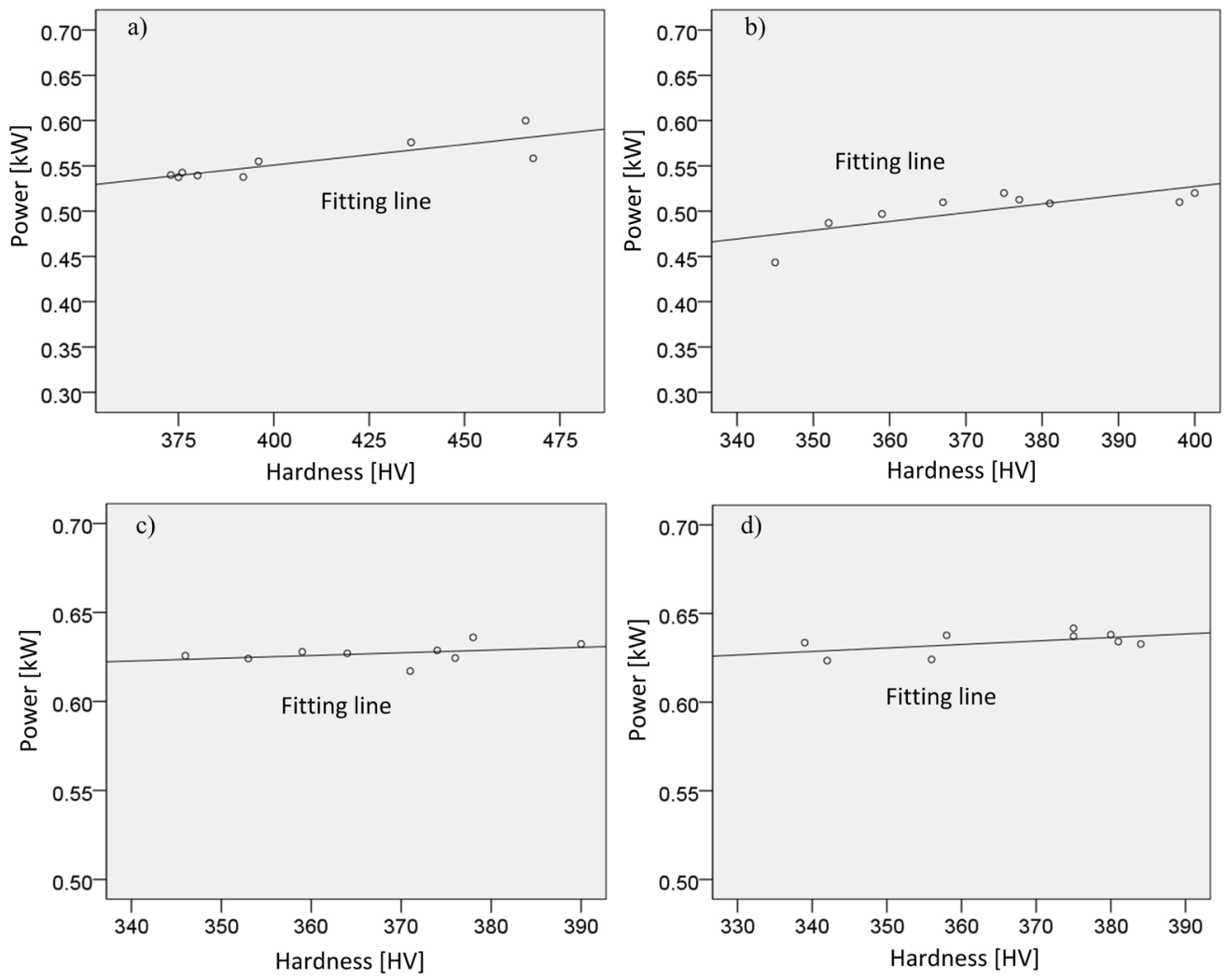

Fig. 11. Scatter graphs and fitting lines of variable power and variable hardness; a) feed rate $=300 \mathrm{~mm} / \mathrm{min}, \mathrm{Z}$ feed direction; b) feed rate $=300 \mathrm{~mm} / \mathrm{min}, X$ feed direction; c) feed rate $=600 \mathrm{~mm} / \mathrm{min}, Z$ feed direction; d) feed rate $=600 \mathrm{~mm} / \mathrm{min}, X$ feed direction 
times. Locations of test points on the metallographic sample surface are in Fig. 6. The average value of every test point is calculated for accuracy. Hardness curves are created and compared to corresponding grinding power signal shown in Fig. 10. For example, Fig. 10a has two parts: the red curve is the hardness curve marked with number 1 to 9 ; the blue signal is the time domain grinding power signal, whose peak power values are also marked with numbers 1 to 9. The grinding power signal is collected at a feed rate of $300 \mathrm{~mm} / \mathrm{min}$ along the $\mathrm{Z}$ feed direction. The black curve through the grinding power peak value points represents the grinding power consumption because of the same idle power value. As can be seen from Fig. 10, peak power curve shows the similar trend with the hardness curve. Therefore, correlation detection is conducted to investigate the correlation of microhardness with corresponding grinding power consumption.

To determine the correlation between hardness and peak grinding power, Pearson correlation calculation and $\mathrm{T}$ significance test are conducted. Before calculating the Pearson correlation coefficient, the scatter graphs and fitting lines (Fig. 11) of the variable power and the variable hardness are drawn to show the correlation of power and hardness qualitatively. The feed rate and feed direction are marked in Fig. 11. Data sets (a), (b), (c), and (d) in Fig. 11 are the same as in Fig. 10, respectively. The linear regression equation is calculated by using the least square method and shown as a fitting line in Fig. 11. It indicates linear correlation between power and hardness. To evaluate the correlation between power and hardness quantitatively, Pearson correlation calculation and $\mathrm{T}$ significance test are performed. The result of correlation analysis indicates that microhardness and grinding power consumption have significant correlation at the conference level of $95 \%$ illustrated in Table 6 . It should be noted that Figs. 10 and 11 and Table 6 share the same data sets and reveal the same regularity from different aspects. Correlation analysis results in Table 6 reveals the regularity: the higher microhardness of material microstructure means higher grinding power consumption with the same grinding parameters. Therefore, the microstructure of the material will influence the grinding process (e.g. grinding power) through influencing the hardness of the corresponding microstructure.

Table 6. Correlation analysis result for hardness value and grinding power consumption

\begin{tabular}{ccccc}
\hline $\begin{array}{c}\text { Data } \\
\text { sets }\end{array}$ & $\begin{array}{c}\text { Sample } \\
\text { number }\end{array}$ & $\begin{array}{c}\text { Pearson } \\
\text { correlation } \\
\text { coefficient }\end{array}$ & $\begin{array}{c}\text { Significance } \\
\text { coefficient } \\
\text { (2-tailed) }\end{array}$ & $\begin{array}{c}\text { Significance } \\
\text { level }\end{array}$ \\
\hline (a) & 9 & 0.798 & 0.010 & Yes (at 0.05 level) \\
\hline (b) & 9 & 0.812 & 0.027 & Yes (at 0.05 level) \\
\hline (c) & 9 & 0.713 & 0.048 & Yes (at 0.05 level) \\
\hline (d) & 9 & 0.649 & 0.042 & Yes (at 0.05 level) \\
\hline
\end{tabular}

\subsection{Surface Roughness vs. Microstructure}

These eight surfaces to be tested have different grinding parameters (see Table 5). The average roughness value grows as the working table speeds up in the same feed direction (Fig. 12a). The standard deviation of five roughness values can be calculated to represent the fluctuation condition in one testing area. The standard deviation of roughness along the $\mathrm{X}$ feed direction is smaller than that along the $\mathrm{Z}$ feed direction in the same feed rate (Fig. 12b). Consequently, the roughness along the $\mathrm{X}$ feed direction shows more stable characteristics than that in the $\mathrm{Z}$ feed direction.
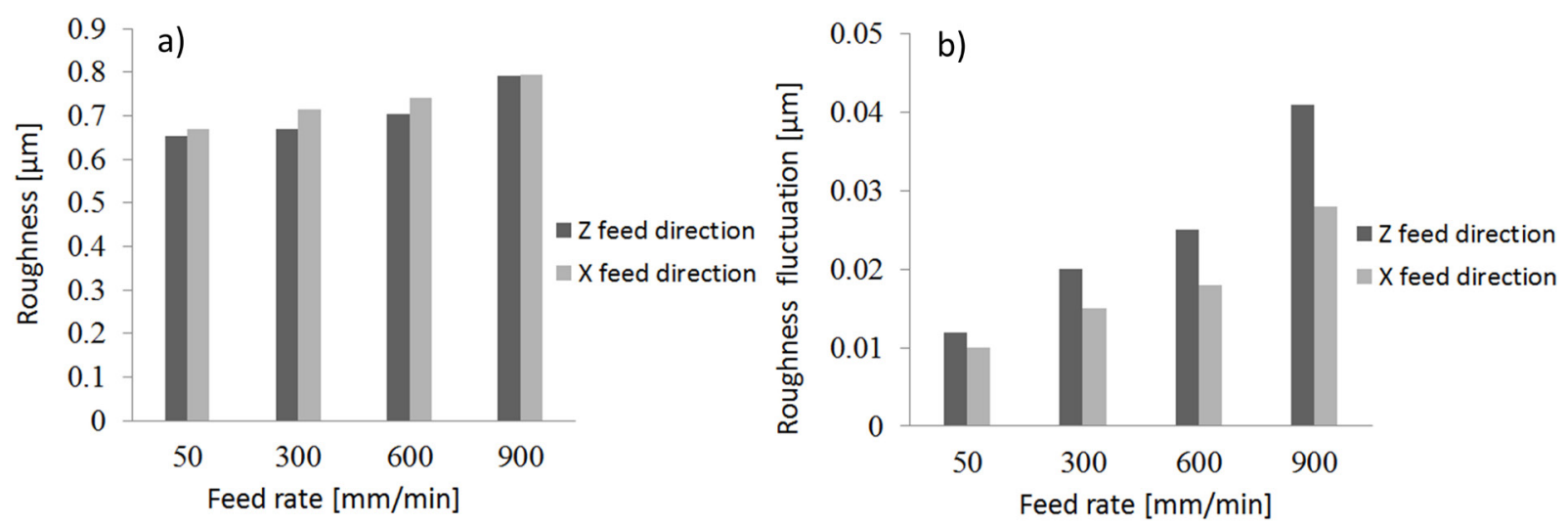

Fig. 12. a) Roughness values and b) fluctuations for eight finished surfaces with different parameters 
The microstructure difference between the scanning plane and side plane can explain the above phenomenon. As depicted in Figs. $8 \mathrm{~b}$ and $\mathrm{c}$, the grinding process can be regarded as cutting process combinations of numerous wheel grits. Because of the layered structure and scaly structure, the material removal mechanisms along the $\mathrm{X}$ and $\mathrm{Z}$ directions are quite different. Firstly, hardness varies from the boundary to the interior of the scaly structure because of the crystallization process. Additionally, Figs. $8 \mathrm{~b}$ and $\mathrm{c}$ indicate that grit will go through fewer scaly structures along the $\mathrm{X}$ feed direction compared to the $\mathrm{Z}$ feed direction during the same distance. Therefore, smaller hardness fluctuation will result in smaller cutting force fluctuation along the $\mathrm{X}$ direction for a single grit. Although the morphology and orientation of grits are not uniform, the entire grinding force will behave in a similar manner as the cutting force of a single grit considering the comprehensive effect of numerous grits. Because the stability of the grinding force has great influence on ground surface quality, better surface homogeneity and smaller roughness fluctuation will be obtained along the $\mathrm{X}$ feed direction due to smaller grinding force fluctuation. Furthermore, this difference will be more obvious as the feed rate increases.

\section{CONCLUSIONS}

In this study, the grindability of SLM Inconel 718 superalloy has been experimentally investigated. First, metallographic photos are taken to determine the difference of microstructures between the scanning plane and side plane. Grinding power signal, microhardness profile, and ground surface roughness exhibit anisotropy because of the anisotropic microstructure. The major findings can be summarized as below:

1. Structure composition and crystalline form are quite different between the scanning plane and side plane of SLM Inconel 718 material. The scanning plane consists of many strip structures along the scanning direction while the side plane is characterized by scaly structures and layered structures. The scanning plane is characterized by equiaxed grain while the side plane is characterized by columnar dendrites along the building direction.

2. The microhardness profile along the building direction varies significantly compared to the scanning direction. Furthermore, the hardness curve along the building direction in the side plane has periodicity owing to the layered structure.

3. The grinding layer with higher hardness requires higher grinding power consumption. The grindability of SLM material exhibits anisotropy because of the anisotropic microstructure.

4. Better surface homogeneity and smaller roughness fluctuation will be obtained along the scanning direction than the building direction when grinding SLM-processed Inconel 718 material.

\section{ACKNOWLEDGEMENTS}

This research is supported by Project NSAF-U1430116 and Project 2017ZX04007001. The authors would also like to thank the support from Tsinghua University Initiative Scientific Research Program and TsinghuaRWTH Aachen Collaborative Innovation Funding.

\section{REFERENCES}

[1] Trosch, T., Strößner, J., Völkl, R., Glatzel, U. (2016). Microstructure and mechanical properties of selective laser melted Inconel 718 compared to forging and casting. Materials Letters, vol. 164, p. 428-431, D0l:10.1016/j. matlet.2015.10.136.

[2] Wang, X., Gong, X., Chou, K. (2015). Review on powderbed laser additive manufacturing of Inconel 718 parts. Proceedings of the Institution of Mechanical Engineers, Part B: The Journal of Engineering Manufacture, vol. 231, no. 11, p. 1890-1903, Dol:10.1177/0954405415619883.

[3] Zhang, D., Niu, W., Cao, X., Liu, Z. (2015). Effect of standard heat treatment on the microstructure and mechanical properties of selective laser melting manufactured Inconel 718 superalloy. Materials Science and Engineering $A$, vol. 644, p. 32-40, D0l:10.1016/j.msea.2015.06.021.

[4] Wang, Z., Guan, K., Gao, M., Li, X., Chen, X., Zeng, X. (2012). The microstructure and mechanical properties of deposited-IN718 by selective laser melting. Journal of Alloys and Compounds, vol. 513, p. 518-523, D0l:10.1016/j. jallcom.2011.10.107.

[5] Lu, Y., Wu, S., Gan, Y., Huang, T., Yang, C., Lin, J., Lin, J. (2015). Study on the microstructure, mechanical property and residual stress of SLM Inconel-718 alloy manufactured by differing island scanning strategy. Optics \& Laser Technology, vol. 75, p. 197-206, D0l:10.1016/j.optlastec.2015.07.009.

[6] Gong, X., Wang, X., Cole, V., Jones, Z., Cooper, K., Chou, K. (2015). Characterization of microstructure and mechanical property of Inconel 718 from selective laser melting. ASME International Manufacturing Science and Engineering Conference, D0I:10.1115/MSEC2015-9317.

[7] Jia, Q., Gu, D. (2014). Selective laser melting additive manufacturing of Inconel 718 superalloy parts: Densification, microstructure and properties. Journal of 
Alloys and Compounds, vol. 585, p. 713-721, D0l:10.1016/j. jallcom.2013.09.171.

[8] Konečná, R., Kunz, L., Nicoletto, G., Bača, A. (2016). Fatigue crack growth behavior of Inconel 718 produced by selective laser melting. Fracture and Structural Integrity, vol. 10, no. 35, p. 31-40, DOI:10.3221/IGF-ESIS.35.04.

[9] Strößner, J., Terock, M., Glatzel, U. (2015). Mechanical and microstructural investigation of nickel-based superalloy IN718 manufactured by selective laser melting (SLM). Advanced Engineering Materials, vol. 17, no. 8, p. 1099-1105, DOI:10.1002/adem.201500158.

[10] Zhi, G., Li, X., Qian, Z., Liu, H., Rong, Y. (2016). Experimental study of time-dependent performance in superalloy highspeed grinding with cbn wheels. Machining Science \& Technology, vol. 20, no. 4, p. 615-633, D0l:10.1080/109103 44.2016.1224018.

[11] Devillez, A., Le Coz, G., Dominiak, S., Dudzinski, D. (2011). Dry machining of Inconel 718 , workpiece surface integrity. Journal of Materials Processing Technology, vol. 211, no. 10, p. 15901598, D0I:10.1016/J.jmatprotec.2011.04.011.

[12] Pusavec, F., Hamdi, H., Kopac, J., Jawahir, I.S. (2011). Surface integrity in cryogenic machining of nickel based alloy-Inconel 718. Journal of Materials Processing Technology, vol. 211, no. 4, p. 773-783, DOI:10.1016/j.jmatprotec.2010.12.013.

[13] Yao, C.F., Jin, Q.C., Huang, X.C., Wu, D.X., Ren, J.X., Zhang, D.H. (2013). Research on surface integrity of grinding Inconel718. International Journal of Advanced Manufacturing Technology, vol. 65 , no. 5-8, p. 1019-1030, Dol:10.1007/s00170-0124236-7.

[14] Ding, W., Dai, J., Zhang, L.C., Xu, J. (2014). An investigation on the chip formation and forces in the grinding of inconel718 alloy using the single-grain method. Issues in Mental Health Nursing, vol. 28, no. 1, p. 1-2.

[15] Chen, Z Z., Xu, J.H., Ding, W.F., Ma, C.Y., Fu, Y.C. (2015). Grinding temperature during high-efficiency grinding Inconel 718 using porous CBN wheel with multilayer defined grain distribution. International Journal of Advanced Manufacturing Technology, vol. 77, no. 1-4, p. 165-172, D0l:10.1007/s00170014-6403-5.

[16] Sinha, M.K., Madarkar, R., Ghosh, S., Rao, P.V. (2015). Productivity improvement through suitable selection of conventional abrasive wheel in grinding of Inconel 718 superalloy. International Conference on Industrial Engineering, p. 1-6.

[17] Zhang, B., Lee, X., Bai, J., Guo, J., Wang, P., Sun, C.N., Nai, M., Qi, G., Wei. J. (2017). Study of selective laser melting (SLM) Inconel 718 part surface improvement by electrochemical polishing. Materials \& Design, vol. 116, p. 531-537, D0I:10.1016/j.matdes.2016.11.103.

[18] Jhabvala, J., Boillat, E., Antignac. T., Glardon, R. (2010). On the effect of scanning strategies in the selective laser melting process. Virtual \& Physical Prototyping, vol. 5, no. 2, p. 99109, D0l:10.1080/17452751003688368. 